\title{
Cell proliferation patterns in canine infundibular keratinizing acanthoma and well differentiated squamous cell carcinoma of the skin
}

\author{
L. Della Salda ${ }^{1}$, R. Preziosi, M. Mazzoni and P.S. Marcato
}

${ }^{1}$ Department of Functions, Structures, Animal Pathology and Biotechnology, University of Teramo, and Department of Veterinary Public Health and Animal Pathology, via Tolara di Sopra 50-40064 Ozzano Emilia University of Bologna, Italy

Accepted: 6/2/2002

Key words: proliferative indices, dog, tumours, MIB1, AgNOR

\section{SUMMARY}

The aim of the present study was to investigate if the evaluation of cell proliferation of the well differentiated squamous cell carcinoma (WDSCC) and infundibular keratinizing acanthoma (IKA) could be useful in the differential diagnosis between these two tumours. Eighteen IKAs and ten WDSCCs were selected for this study. Two different methods were used to assess the activity of cell proliferation: MIB1 immunohistochemical detection and AgNOR proteins silver staining. The quantification of proliferative parameters was performed by means of an image analyzer and expressed as MIB1 index and AgNOR area (MNORA). Both MIB1 immunohistochemical and AgNOR histochemical patterns were different in WDSCC and IKA; moreover analysis of variance showed a significant difference for both parameters employed (MIB1 index, MNORA) between WDSCC and IKA ( $\mathrm{P}<0.003$ for MIB1 index; $\mathrm{P}<0.0001$ for AgNOR area). The results show that canine WDSCC and IKA have a different proliferative behaviour and the assessment of cell proliferation can be considered as a useful adjunctive tool to the histopathological investigation in the differential diagnosis of these tumours.

\section{INTRODUCTION}

Canine well differentiated squamous cell carcinomas (WDSCC) of the skin are erosive, plaque-like lesions comprising islands and trabeculi of squamous cells that originate from the epidermis and extend into the dermis (Gross et al. 1992). In contrast, infundibular keratinizing acanthoma (IKA) is a benign follicular neoplasm of dogs that evolves rapidly, forming a solitary or multiple firm, flaskshaped cystic nodules with keratin in their centres (Rudolph et al. 1977, Yager and Scott 1993). It is important that this benign tumour is not misdiagnosed histopathologically as WDSCC, which is a locally destructive disease with a considerable risk of local recurrence and regional invasion (Yager and Scott 1993, Yager and Wilcock 1994).

In the IKA, the neoplastic growth into the surrounding dermis is by blunt cords of well differentiated squamous epithelium with a continuous border of basal cells (Stannard and Pulley 1975, Goldschmidt and Shoefer 1992). This histopathological archtectural pattern distinguishes this tumour from WDSCC in which there are invasive cords consisting of atypical keratizing cells in direct contact with the dermis without a basal cell

Correspondence to: R. Preziosi

E-mail: preziosi@vet.unibo.it 
rim (Yager and Scott 1993, Yager and Wilcock 1994). Sometimes, however, histological criteria alone may be not enough to make the distinction between IKA and WDSCC. When small skin biopsies are submitted to the pathologist, it may be difficult to evaluate the different growth pattern of these two tumours normally considered the most useful histological criterion in the differential diagnosis between IKA and WDSCC.

It is widely accepted that the assessment of cell proliferation is an important indicator of clinical behaviour in many types of tumours (Hall and Levison 1990) and it can be used for diagnostic and prognostic purposes as a reliable adjunct to conventional clinico-pathological criteria. The monoclonal antibody MIB1, which detects an epitope of Ki-67protein on routinely processed paraffin-wax embedded tissue sections, allows the immunohistochemical identification of a nuclear antigen specific to dividing (cycling) cells and offers a good approach to the evaluation of the growth fraction (Linden et al. 1992, Matsuta et al. 1996). AgNOR proteins are a group of argyrophilic proteins closely associated to nucleolar organizer regions (NORs) and the evaluation of the AgNOR quantity, being strictly related to the cell duplication rate (Trerè et al. 1989), is thought to be a useful proliferation marker which is technically easy to perform (Hirai et al. 2001; Iwasa et al. 2001; Khaled et al., 2000; Trerè et al. 1996; Tsuzuki et al., 1994).

In this study we have used these two assays of cell proliferative activity, to investigate if the pattern and/or grade of cell proliferation might be useful in making the distinction between these two tumours and if it is correlated with different clinical behaviour of these two neoplastic lesions.

\section{MATERIALS AND METHODS}

Ten (10) cutaneous WDSCCs and eighteen (18) IKAs were selected from dogs for this study. All the dogs underwent surgery at the University Clinic of Veterinary Surgery or by private practices and the biopsy material was submitted to the Veterinary Pathology service of the University of Bologna, immediately fixed in 10\% neutral formalin and routinely processed. Histopathological diagnoses were made on haematoxylin and eosin-stained sections according to the criteria of WHO (1998).

\section{AgNOR method}

Tissues were stained according to the protocol of the standardized AgNOR method (Öfner et al. 1994). Dewaxed sections were immersed in citrate buffer at $\mathrm{pH} 6.0$ and incubated for four periods of 5 minutes each in a microwave oven at $750 \mathrm{~W}$. After cooling to room temperature (RT), the sections were washed in bidistilled water, and stained with a fresh solution of one volume $2 \%$ gelatine in $1 \%$ aqueous formic acid and two volumes $50 \%$ silver nitrate, at $37^{\circ} \mathrm{C}$ for $14 \mathrm{~min}$ in the dark. Following a thorough rinsing with ultrapure water, the sections were washed in distilled water, dehydrated and mounted in Canada Balsam.

\section{MIB1 immunohistochemistry}

The sections were dewaxed in toluene and rehydrated in a graded acetone series (acetone 100: two immersions of 10 min each; acetone 70: 10 min; acetone 50: $10 \mathrm{~min}$ ). Endogenous peroxidase was blocked by means $3 \%$ hydrogen peroxide for $30 \mathrm{~min}$; then sections were rinsed in Tris buffer, immersed in citrate buffer ( $2.1 \mathrm{~g}$ citric acid monohydrate/l distilled water), $\mathrm{pH}$ 6.0, and incubated for four periods of $5 \mathrm{~min}$ each in a microwave oven at $750 \mathrm{~W}$. After microwave irradiation, sections were allowed to cool down to RT (approximately $20 \mathrm{~min}$ ). The primary antibody, known as clone MIB1 (mouse anti- human proliferation antigen expressed in all cell cycle phases of proliferating cells, diluted 1:30 and recognizing on formalin-fixed and paraffin-wax embedded sections the same antigen as $\mathrm{Ki}-67$ on frozen sections) (Immunotech, Int, Marseilles, France) was followed by a highly sensitive streptavidin-biotinperoxidase technique with a commercial kit (BIO SPA, Milan, Italy). In control sections, the primary antibody was substituted by PBS buffer.

\section{Scoring method}

Quantitative analysis was performed with the image cytometer Cytometrica (Byk Gulden, Milano, Italy).

\section{AgNORs}

Quantitative evaluation of interphase AgNORs was performed by measuring the area (square micrometers) occupied by AgNOR dots (AgNOR area). Every image was obtained with the 40x objective. One hundred neoplastic cells were eval- 

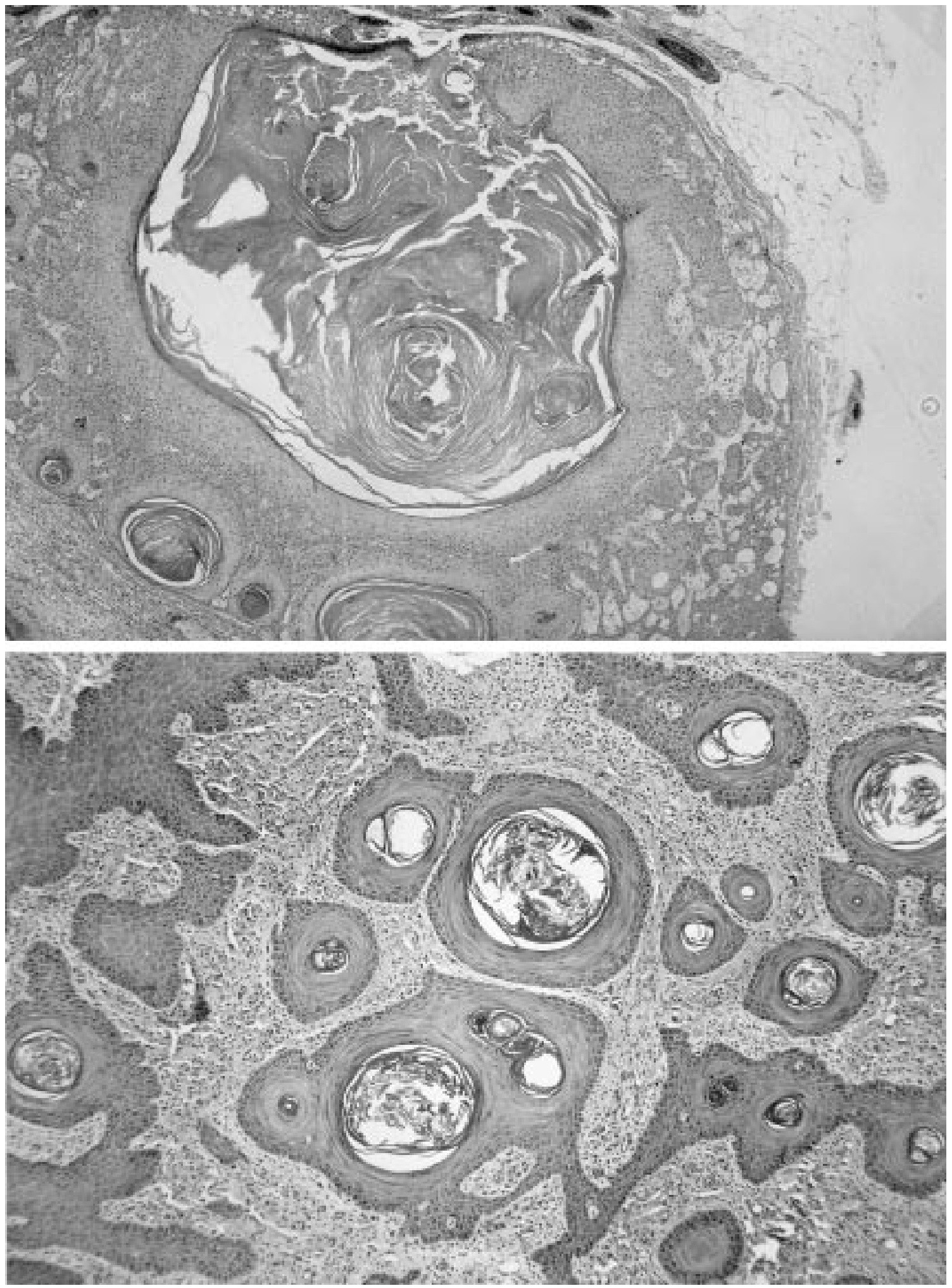

Figs. 1/2 - (1)dog - infundibular keratinizing acanthoma (IKA) - (Haematoxylin and Eosin - x 212) original magnification). (2)dog - well differentiated squamous cell carcinoma (WDSCC) - (Haematoxylin and Eosin - $\mathrm{x} 212$ original magnification). 
uated for each case (4 fields and 25 cells for each field) and the content of AgNOR proteins was expressed as mean AgNOR area.

\section{MIB1 index}

For each case the observer selected 10 fields with the highest positivity to MIB1 using a 25x objective. In each field, a first image was mapped with a green $(575 / 10 \mathrm{~nm})$ bandpass filter; a second area consisting of all the MIB1 positive nuclei was mapped with a blue $(490 / 10 \mathrm{~nm})$ bandpass filter. In each field, inflammatory or stromal cells were erased. MIB1 index was calculated as the percentage of labelled nuclei compared with the total nuclear area.

MIB1 index is expressed as:

total nuclear area of the positively stained nuclei in 10 fields x 100; total nuclear area in 10 fields.

\section{Statistical analysis}

Statistical analyses were performed according to criteria of Camussi et al. (1991) using the software CSS statistica (Statsoft Inc., Tulsa, OK). Differences between the values of the two parameters used (MIB1 index and AgNOR proteins) were assessed by the analysis of variance (ANOVA) to compare the proliferative activity among WDSCC and IKAs.

The analysis of linear regression was performed to test the level of correlation between the two proliferative indices. The results are reported as mean \pm standard error. Difference for analyses were considered significant at $\mathrm{P}<0.005$.

\section{RESULTS}

Cases of IKA and WDSCC selected for this study showed, on haematoxylin and eosin stained sections, the typical histological appearance; in the IKAs the histological lesion was a simple or multiloculated cyst filled with keratin and lined by a wall of stratified squamous epithelium (Fig. 1). In the typical WDSCC, the tumour cells formed anastomosing invasive cords with atypical cells most closely resembling those of stratum spinosum (Fig. 2).

In our investigation, out of the 28 samples stained with MIB1 monoclonal antibody, 19 showed a clear positive staining, and 9 were discarded because they showed no or weak reaction to MIB1. The lack of reactivity of these cases was probably due to a prolonged formalin-fixation of the sam- ples which has destroyed the antigen. The MIB1 immunostaining was confined to the nuclei and was expressed as a brown nuclear staining often with a prominent nucleolar positivity.

In IKAs, the proliferating cells were regularly restricted to the outermost one or two layers of tumour lobules while the keratinized central cells were devoid of MIB1 immunoreactivity (Fig. 3a). The MIB1 positive cells in WDSCC were found dispersed throughout the entire tumour nests, while no peripheral cell staining pattern as seen in IKAs, was seen in these tumours (Fig. 3b).

In this study, the use of the standardized AgNOR staining method allowed us to gain, in all processed specimens, an excellent staining quality of AgNOR proteins, which appear as black dots of different shape and size, scattered in the light yellow nuclear background. In IKAs, AgNORs dots are fully aggregated to form one or more rounded argyrophil structures, often called an AgNOR but more correctly corresponding to the nucleolus (Fig. 3c). In WDSCCs, AgNORs pattern is characterized by clusters of irregular shape where, often, several silver stained dots are close together, so that their edges are not clearly distinguishable (Fig. 3d).

The mean of growth fraction, expressed by MIB1 index, was $10.63( \pm 1.13)$ in IKAs and $18.87( \pm 2.40)$ in WDSCC. The mean AgNOR area was $3.74( \pm 0.34)$ in IKAs and $7.01( \pm 0.80)$ in WDSCC. ANOVA test showed a significant difference in MIB1 index and AgNOR area between WDSCCs and IKAs $(\mathrm{P}<0.003$ for MIB1 index; $\mathrm{P}<0.0001$ for AgNOR area) (Fig. 4, 5).

The analysis of linear regression between AgNOR area and MIB1 index showed a close correlation among the two proliferative indices $(\mathrm{P}<0.0002$; $r=0.74$ ) (Fig.6).

\section{DISCUSSION}

In human medicine, the relationship between infundibular keratinizing acanthoma (keratoacanthoma) and squamous cell carcinoma has been widely debated by dermatopathologists. Some authors are of the opinion that IKA is a characteristic, well defined entity with a distinct histogenesis from WDSCC (Schnur and Bozzo 1978, Lawrence and Reed 1990); others believe that it is a form of 

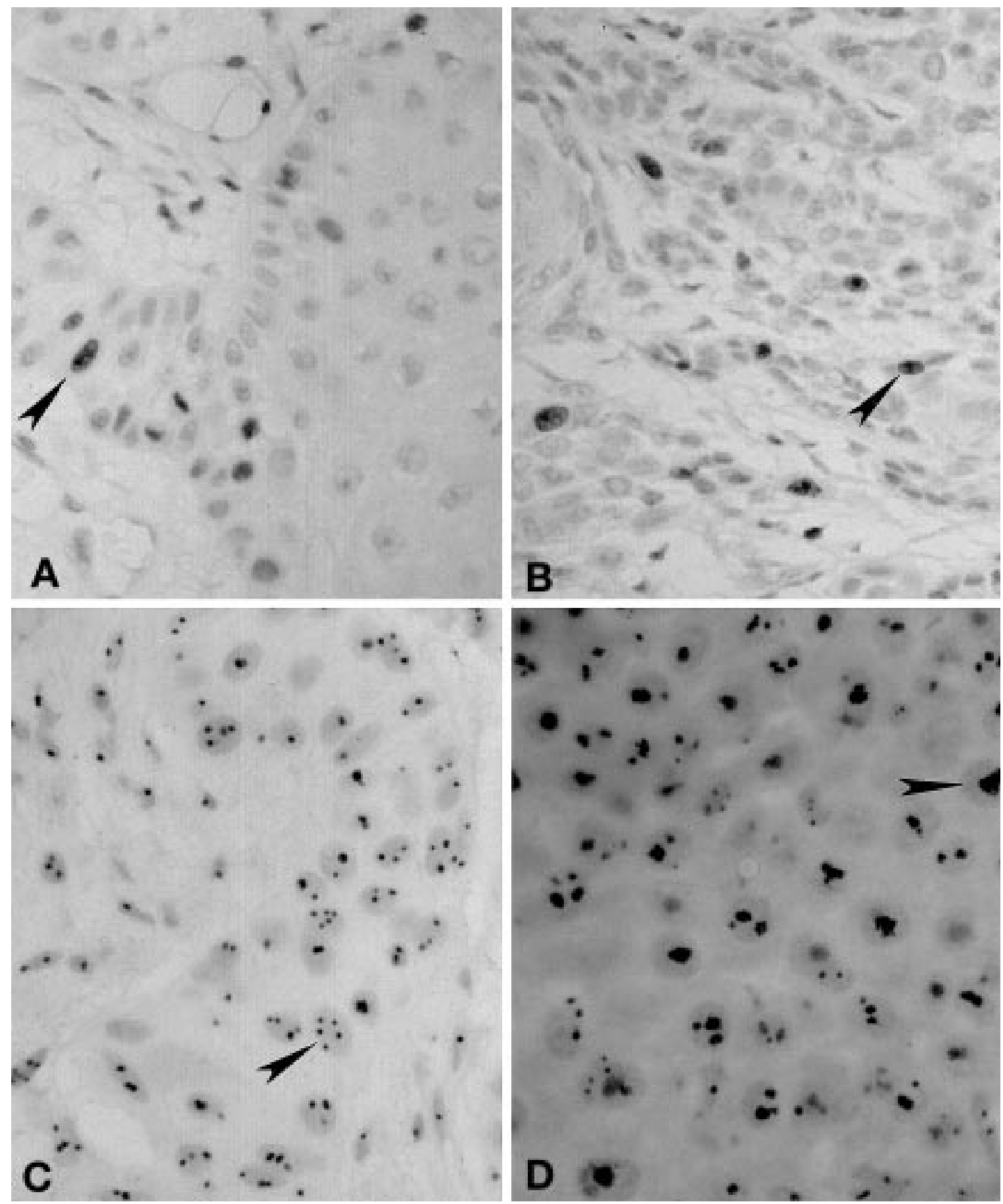

Fig. 3 - (a)dog - infundibular keratinizing acanthoma (IKA) - proliferating cells are regularly restricted to the outermost layers of cells (arrowhead) - (MIB1 immunostaining - x 426 original magnification). (b)dog - well differentiated squamous cell carcinoma (WDSCC) - MIB1 positive cells are distributed diffusely in the tumour nests (arrowhead) - (MIB1 immunostaining - $\mathrm{x} 426$ original magnification). (c)dog - infundibular keratinizing acanthoma (IKA) - AgNOR proteins appear as black dots of different shape and size, scattered in the light yellow nuclear background. (arrowhead) - (AgNOR silver staining - x 672 original magnification). (d) dog - well differentiated squamous cell carcinomas (WDSCC) - AgNORs pattern is characterized by clusters of irregularly shaped multiple dots. (arrowhead) - (AgNOR silver staining - x 672 original magnification) . 


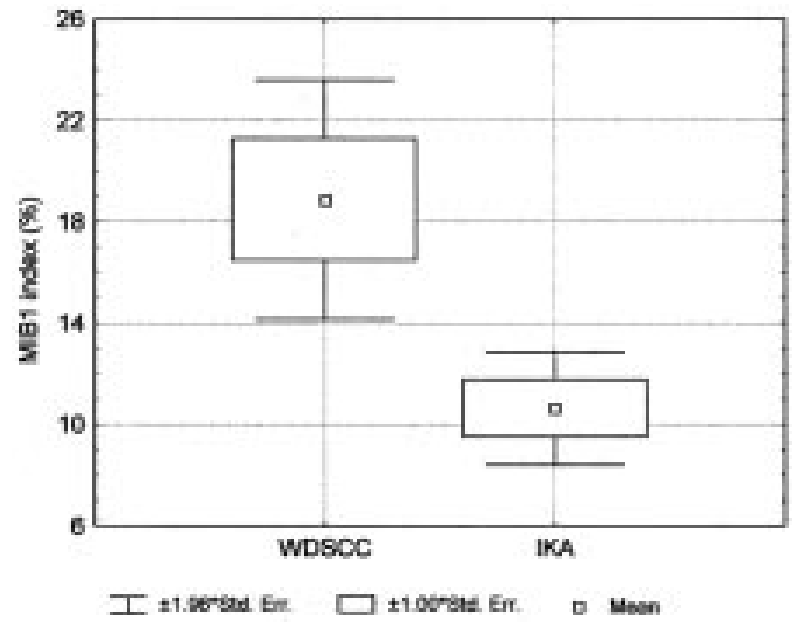

Fig. 4 - values of proliferative activity (mean values \pm standard error), expressed as MIB1 index (\%), in 8 canine well differentiated squamous cell carcinomas $(18.87 \pm 2.40)$ and 11 infundibular keratinizing acanthoma $(10.63 \pm 1.13)$. (ANOVA test: $\mathrm{P}<0.003)$.

squamous cell carcinoma that often spontaneously involutes (Sleater et al. 1994, Le Boit 1995); yet others believe that IKA is an early benign proliferative lesion turning into the typical squamous cell carcinoma, with a variety of lesions with features intermediate between the two (Goldenharsh and Olsen 1984, Poleksic and Yeung 1978).

The IKA of dogs has been compared with keratoacanthoma of man in different studies (Rudolph et al. 1977, Stannard and Pulley 1975). The two tumours are similar in the following respects: a solitary and a generalized form occur; they are benign neoplasms and they occur mostly in males. However, they differ in the following points: epithelium of origin, rate of growth, infiltration and spontaneous involution (Rudolph et al. 1977). So, although they are similar in many respects, they are not identical entities. Moreover, there is no evidence, in canine IKAs, of cytological features of atypia and/or carcinoma-like histological patterns, as recognized in the so-called keratoacanthoma-like squamous cell carcinomas of man (Cain et al. 1995). The use of different methods to assess cell proliferative activity "in situ" for diagnostic and prognostic purposes may be considered as a reliable tool in the histopathological examination. However, these methods, applied in human medicine to investigate the relationship between IKAs and WDSCCs, have not made unequivocal differen-

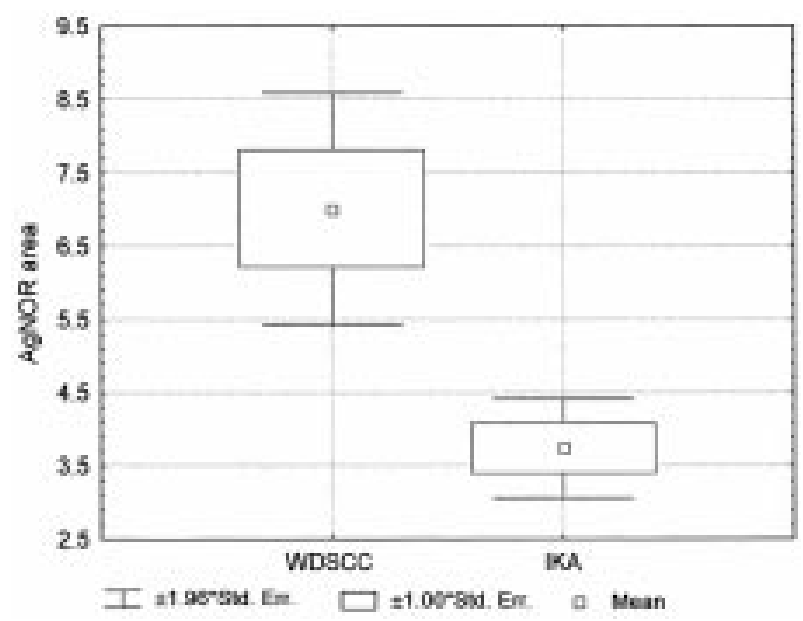

Fig. 5 - values of proliferative activity (mean values \pm standard error), expressed as mean AgNOR area $\left(\mu m^{2}\right)$ in 10 canine well differentiated squamous cell carcinomas (7.01 \pm $0.80)$ e 18 (3.74 \pm 0.34$)$. (ANOVA test $\mathrm{P}<0.0001$ ).

tial diagnosis between these tumours possible.

Most of the immunohistochemical investigations performed in human medicine using antisera to $\mathrm{Ki}$ 67 or to proliferating cell nuclear antigen (PCNA), showed two different patterns of nuclear immunoreactivity: a positive staining only in basal and suprabasal cells in IKAs and a diffusely positive staining in the tumour cells of WDSCCs (Le Boit 1995, Cain et al. 1995, Geary and Cooper 1992, Penneys et al. 1992, Saida et al. 1992, Phillips and Helman 1993, Skàlovà and Michal 1995, Tsuji 1997). In contrast, this difference is not so evident in those cases which Cain et al. (1995) termed keratoacanthoma-like squamous cell carcinomas showing an intermediate histological appearance by conventional microscopy and mixed patterns of immunohistochemical expression. These findings support the concept that the two neoplastic conditions are intimately related and that IKAs may turn into squamous cell carcinomas. Our results have shown, for the MIB1 immunoreactivity, that the pattern of proliferating cells differs substantially in canine IKAs and WDSCCs. These findings may be very useful in the differential diagnosis between IKA and WDSCC and emphasize the different nature of these two neoplastic entities.

AgNORs staining pattern is different in the two types of tumours also, and this difference may be useful for diagnostic purposes. As reported by Crocker $e t$ 


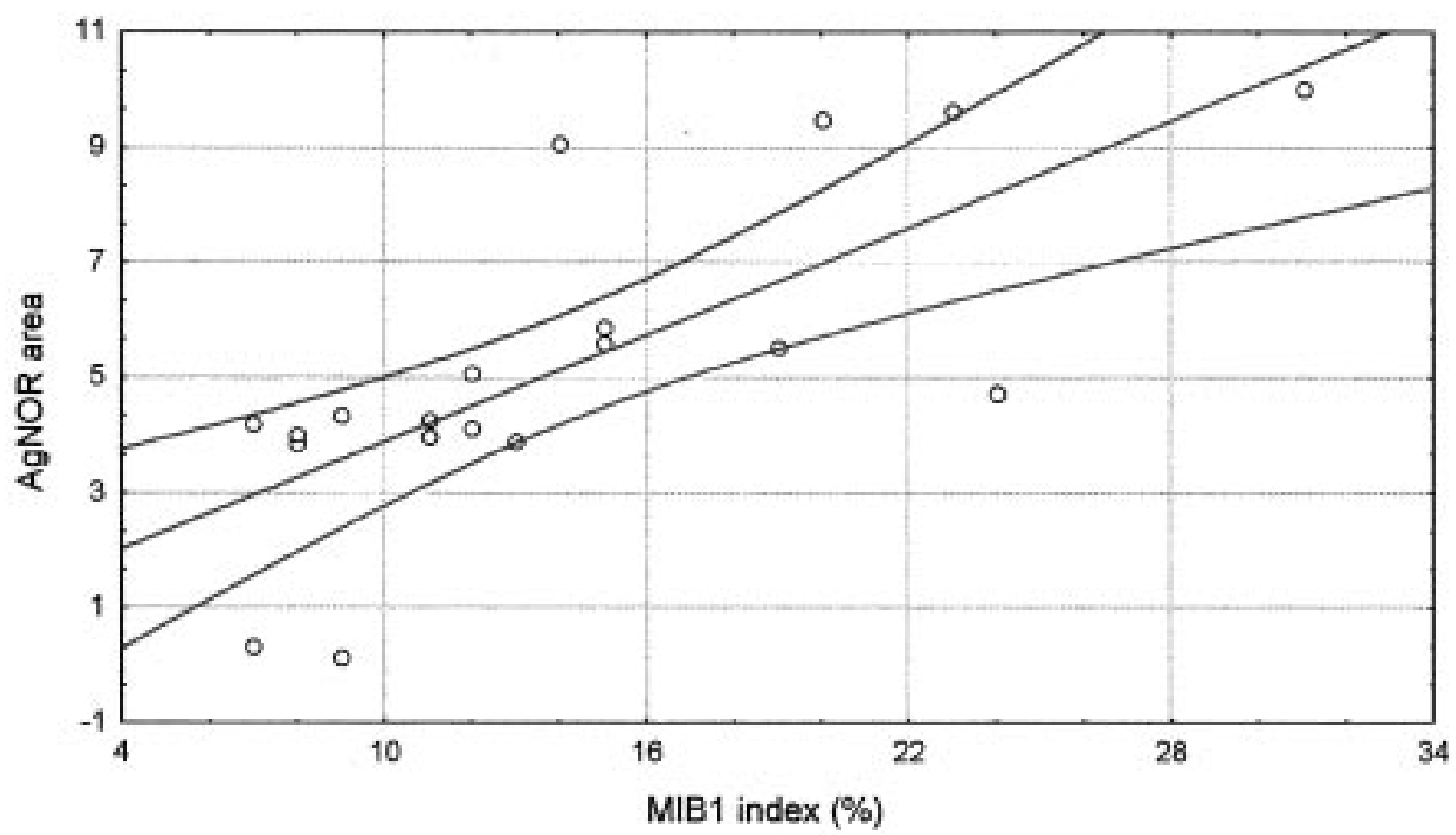

Fig. 6 - Linear regression of MIB1 index $(\%)$ and AgNOR area $\left(\mu \mathrm{m}^{2}\right)$ in 8 canine well differentiated squamous cell carcinomas and 11 infundibular keratinizing acanthoma. Correlation coefficient $=0.74, \mathrm{P}<0.0002$.

al. (1989), AgNOR staining pattern in WDSCC is typical of actively proliferating cells and is the expression of a nucleolar disaggregation with a corresponding increase of AgNOR proteins in S-phase. This proliferative pattern, characterized by multiple and different shaped dots, may be well-correlated with the invasive behaviour of the typical squamous cell carcinoma, and it is expressed as a specific feature by neoplastic cells spreading through the dermis as anastomosing squamous cords.

Quantitative assessment by image analysis has showed, for both the parameters used in this study (MIB1 index and AgNOR area), a clear difference between WDSCCs and IKAs, in accordance with the different clinical behaviour of these two neoplastic diseases and supporting once more the diagnostic usefulness of these methods. The lack of a significant difference in proliferative activity, as reported by many studies in human medicine, suggests the possibility of a transition from a presumed premalignant lesion (IKA) into a frank malignant process (WDSCC) (Goldenharsh and Olsen 1984, Cain et al. 1995).

In conclusion, the results of our study have demonstrated that, in dogs, the difference in pro- liferative behaviour between IKA and WDSCC is both qualitative and quantitative. Moreover this information can be helpful in histological examination in distinguishing between these two neoplastic entities and supports once again that IKA must be considered an entity clinically and histologically distinct from well-differentiated squamous cell carcinoma.

\section{REFERENCES}

Cain C.T., Niemann T.H., and Argenyi Z.B.: Keratoacanthoma versus squamous cell carcinoma. An immunohistochemical reappraisal of $\mathrm{p} 53$ protein and proliferating cell nuclear antigen expression in keratoacanthoma-like tumors. Am. J. Dermatopath. 17, 324-331, 1995.

Camussi A., Möller F., and Ottaviano E.: Metodi Statistici per la sperimentazione biologica - $4^{\circ}$ ed., edizioni Zanichelli, Bologna, 1991.

Crocker J., Boldy D.A.R., and Egan M.J.: How should we count AgNORs? Proposals for a standardized approach. J. Path. 158, 185-188, 1989.

Geary W. A., and Cooper P. H. : Proliferating cell nuclear antigen in common epidermal lesions. J. Cut. Path. 19, 458468, 1992. 
Goldenharsh M.A., and Olsen T.G. : Invasive squamous cell carcinoma initially diagnosed as a giant keratoacanthoma. J. Am. Acad. Derm. 10, 372-378, 1984.

Goldschmidt M.H., and Shoefer F.S.: Skin tumours of the dog and cat. Pergamon Press: Oxford, 109-114, 1992.

Goldschmidt M.H., Dunstan R.W., Stannard A.A., Von Tscharner C., Walder E.J., and Yager J.A.: Histological Classification of Epithelial and Melanocytic Tumors of the Skin of Domestic Animals. In: WHO International Histological Classification of Domestic Animals, series $2^{\text {nd }}$, vol. 3, 1998.

Gross T.L., Ihrke P.J., and Walder F.J.: Veterinary Dermatopathology. St. Louis: Missouri, 330-373, 1992.

Hall P.A., and Levison D.A.: Review: assessment of cell proliferation in histological material. J. Clin. Path. 43, 184-192, 1990.

Hirai K., Kumakiri M., Ueda K., Imamura Y., Noriki S., Nishi Y., Kato H. and Fukuda M.: Clonal evolution and progression of 20-methylcholanthrene-induced squamous cell carcinoma of mouse epidermis as revealed by DNA-instability and other malignancy markers. Eur. J. Histochem. 45, 319-332, 2001.

Iwasa M., Imamura Y., Noriki S., Nishi Y., Kato H. and Fukuda M.: Immunohistochemical detection of early-stage carcinogenesis of oral leukoplakia by increased DNA-instability and various malignancy markers. Eur. J. Histochem. 45, 333-346, 2001.

Khaled A., Imamura Y., Noriki S. and Fukuda M.: Early progression stage of malignancy of uterine cervical dysplasia as revealed by immunohistochemical demonstration of increased DNA instability. Eur. J. Histochem. 44, 143-156, 2000.

Lawrence N., and Reed R.J.: Actinic keratoacanthoma: Speculations on the nature of the lesion and the role of cellular immunity in its Evolution. Am. J.Derm. 12 (5), 517-533, 1990.

Le Boit P.E.: Is keratoacanthoma a variant of squamous cell carcinoma. Am. J. Derm. 17(4), 319-320, 1995.

Linden M.D., Torres F.X., Kubus J., and Zarbo R.S.: Clinical application of morphologic and immunocytochemical assessment of cell proliferation. Am. J. Path. (Suppl. 1) 97, 4-13, 1992.

Matsuta M., Kimura S., Kosegawa G., Kon S., and Matsuta M.: Immunohistochemical detection of $\mathrm{Ki}-67$ in epithelial skin tumor in formalin-fixed paraffin-embedded tissue sections using a new monoclonal antibody (MIB1). J. Derm. 23, 147-152, 1996.

Öfner D., Baukfalvi A., Riehemann K., Bocker W., and Schmid K.W.: Standardized AgNOR stain method for formalin-fixed and paraffin embedded material. Path. 15, 226-230, 1994.

Penneys N.S., Bogaert M., Serfling U., and Sisto M.: PCNA expression in cutaneous keratinous neoplasms and verruca vulgaris. Am. J. Path. 141, 139-142, 1992.

Phillips P., and Helman K.F.: Proliferating cell nuclear antigen distribution in keratoacanthoma and squamous cell carcinoma. J.Cut.Path. 20, 424-429, 1993.

Poleksic S., and Yeung K.Y.: Rapid development of keratoacanthoma and accelerated trasformation into squamous cell car- cinoma of the skin. A mutagenic effect of polychemiotherapy in a patient with Hodgkin's Disease? Cancer 41, 12-16, 1978.

Rudolph R., Gray A.P., and Leipold H.W.: Intracutaneous cornifyng epithelioma ("keratoacanthoma") of dog and keratoacanthoma of man. Corn. Vet. 67, 254-264, 1977.

Saida T., Dohi S., and Sadaki M.: Distribution pattern of proliferating cells in cutaneous keratinocytic neoplasms. J. Am. Acad.Derm. 26, 744-748, 1992.

Schnur P.L., and Bozzo P.: Metastasizing keratoacanthomas? The difficulties in differentiating keratoacanthomas from squamous cell carcinomas. Plas. Rec. Surg. 62, 258-262, 1978.

Skàlovà A, and Michal M.: Patterns of cell proliferation in actinic keratoacanthomas and squamous cell carcinomas of the skin. Am. J. Derm. 17(4), 332-334, 1995.

Sleater J.P., Beers B.B., Stephens C.A., and Hendricks J.B.: Keratoacanthomas: a deficient squamous cell carcinoma? Study of bcl-2 expression. J. Cut. Path. 21, 514519, 1994.

Stannard A.A., and Pulley L.T.: Intracutaneous cornifyng epithelioma (keratoacanthoma) in the dog: A retrospective study of 25 cases. JAVMA 167(5), 385-388, 1975.

Trerè D., Pession A., and Derenzini M.: The silver-stained proteins of interphasic nucleolar organizer regions as a parameter of cell duplication rate. Exp. Cell Res. 184, 131-137, 1989.

Trerè D., Ceccarelli C., Danova M. and Derenzini M.: In vivo bromodeoxyuridine labelling index, AgNOR protein expression and DNA content in human tumours. Eur. J. Histochem. 40, 17-26, 1996.

Tsuji T.: Keratoacanthoma and squamous cell carcinoma: study of PCNA and Le expression. J. Cut. Path. 24, 409-415, 1997.

Tsuzuki H., Saito H., Imamura Y., Noriki S. and Fukuda M.: Early progression stage of malignancy as revealed by immunohistochemical demonstration of increased DNA instability; II, Otorhinolaryngeal borderline neoplastic lesions. Eur. J. Histochem. 38, 291-302, 1994.

Yager J.A., and Scott D.W.: The Skin and Appendages In: Jubb K.V.F., Kennedy P.C., and Palmer N. eds. Pathology of Domestic Animals, Vol. 1, $4^{\text {th }}$ Edition. San Diego: Academic Press, Inc, pp 531-738, 1993.

Yager J.A., and Wilcock P.: Surgical Pathology of the Dog and Cat, Vol. 1. London: Wolfe and Mosby-Year Book Europe Limited eds. pp. 245-256, 1994. 